\title{
GAMBARAN SANITASI KANTIN DI SEKOLAH MENENGAH PERTAMA NEGERI 2 KUTA SELATAN KABUPATEN BADUNG TAHUN 2018
}

\author{
Ni Luh Putu Purnama Dewi ${ }^{1}$, I Nyoman Gede Suyasa ${ }^{2}$
}

\begin{abstract}
Based on preliminary observations, there are four canteen at State Junior High School 2 Kuta Selatan Badung Regency, which in between the canteen is divided into several plots of buildings that are not the same width. Among the four canteen are some of them in terms of buildings and placement locations can be detrimental to people who shop because it is very close to the temporary shelter. Research objectives to know the sanitation of school canteen at State Junior High School 2 Kuta Selatan Sub-district of Kuta Selatan Badung Regency Year 2018. By using descriptive research, writer do observation and interview to canteen and school attendant. The results of this researcher obtained the condition of the building and canteen facility and presentation hygiene got result not fulfill requirement with $50 \%$ percentage and fulfill requirement with $50 \%$ percentage. In the storage of food and beverage equipment all the canteen classified as qualified with 100\% percentage and on the measurement of light intensity results obtained that is $75 \%$ canteen and $25 \%$ eligible eligible. Suggestions that can be submitted to the canteen management, students and teachers and the school to better pay attention to better sanitation for the canteen at the State Junior High School 2 Kuta Selatan Badung Regency 2018.
\end{abstract}

Keywords: Sanitation of the school canteen.

\section{PENDAHULUAN}

Jajanan merupakan salah satu

jenis makanan yang dikenal oleh masyarakat terutama pada anak sekolah. Anak sekolah cenderung untuk mengonsumsi makanan yang dijual dilingkungan sekolah maupun kantin, sehingga kebersihan dan kehigienisan sangatlah ditentukan oleh pedagang. (1). Dalam ruang lingkup kesehatan lingkungan disekolah, kantin merupakan salah satu ruang lingkup yang paling penting untuk mengukur tingkat higiene dan sanitasi suatu sekolah.(2).

Kantin adalah setiap bangunan yang menetap dengan segala peralatan yang dipergunakan untuk proses pembuatan dan penjualan atau penyajian makanan dan minuman, dimana proses pembuatan dan penjualan atau penyajian makanan diperuntukkan bagi masyarakat tertentu (khusus) dan cara penyajian pada waktu - waktu tertentu(3) 
Jurnal Kesehatan Lingkungan Vol.10 No. 1 Mei 2020:1-8

Kantin sekolah adalah tempat di sekolah di mana segenap warga sekolah dapat membeli panganan jajanan, baik berupa pangan siap saji maupun pangan olahan. Kantin sekolah memiliki peranan penting dalam mewujudkan pesan pesan kesehatan dan dapat menentukan perilaku makan siswa sehari - hari melalui penyediaan makanan jajanan di $\operatorname{sekolah}(4)$.

Salah satu fungsi dari kantin adalah sebagai tempat memasak atau membuat dan selanjutnya dihidangkan kepada konsumen, maka kantin dapat menjadi tempat penyebaran segala penyakit yang medianya melalui makanan dan minuman. Dengan demikian makanan dan minuman yang dijual dikantin berpotensi menyebabkan penyakit bawaan makanan bila tidak dikelola dan ditangani dengan baik(5).

Berdasarkan observasi awal yang dilakukan, terdapat empat kantin di Sekolah Menengah Pertama Negeri 2 Kuta Selatan Kabupaten Badung, yang dimana di antara kantin tersebut terbagi menjadi beberapa petak bangunan yang luasnya tidak sama. Sikap penjaga kantin yang tidak menggunakan alat pelindung diri, tidak mencuci tangan sebelum dan sesudah mengolah makanan juga dapat menimbulkan dampak negatif bagi orang yang mengkonsumsi makanan dikantin tersebut. Dengan melihat hal tersebut, tentunya pihak sekolah harus memperhatikan kualitas makanan dan minuman yang dijual dikantin agar terjaminnya kualitas dan mutu makanan yang dijual.

Tujuan penelitian ini yaitu untuk Mengetahui sanitasi kantin di Sekolah Menengah Pertama Negeri 2 Kuta Selatan Kecamatan Kuta Selatan Kabupaten Badung Tahun 2018 yang meliputi kondisi bangunan dan fasilitas, higiene penyajian, penyimpanan peralatan dan makanan dan intensitas cahaya. Manfaat penelitian ini yaitu sebagai sarana masukan kepada penjaga kantin dan pihak sekolah agar dapat tercipta sanitasi kantin yang baik dan memberikan informasi kepada siswa - siswi dan orang yang berbelanja di sekolah tentang pentingnya kualitas sanitasi kantin.

\section{METODE}

Jenis penelitian yang digunakan penulis adalah deskriptif, karena penelitian deskriptif ini merupakan penelitian yang dilakukan terhadap 
Jurnal Kesehatan Lingkungan Vol.10 No. 1 Mei 2020:1-8

sekumpulan objek yang biasanya bertujuan untuk melihat gambaran fenomena (termasuk kesehatan) yang terjadi di dalam suatu populasi tertentu (6). Jenis data penelitian ini yaitu data primer dan data sekunder.

Data primer dalam penelitian ini yaitu dilakukan dengan pengamatan secara langsung menggunakan formulir kuesioner mengenai sanitasi dan melakukan pengukuran pencahayaan menggunakan alat lux meter dan dokumentasi yang diambil pada saat melakukan observasi. Data sekunder yang digunakan diperoleh dari Sekolah Menengah Pertama 2 Kuta Selatan Kabupaten Badung meliputi denah bangunan, gambaran umum lokasi, dan sejarah sejarah berdirinya Sekolah Menengah Pertama 2 Kuta Selatan.

Teknik yang dilakukan yaitu dengan cara pengumpulan data, dalam penelitian ini peneliti menggunakan metode pengumpulan data dengan survai melalui kuesioner(7),dimana data yang didapat kemudian dikumpulkan dan diolah sehingga dapat disajikan dalam bentuk tabel.
HASIL DAN PEMBAHASAN

Sekolah Menengah Pertama

Negeri 2 Kuta Selatan berdiri pada tanggal tanggal 22 Desember 1986.

Berdasarkan penelitian yang telah dilakukan di kantin Sekolah Menengah Pertama Negeri 2 Kuta Selatan, kondisi bangunan dan fasilitas di ke 4 kantin tersebut didapatkan hasil sebagai berikut :

Tabel 1

Kondisi bangunan dan fasilitas di kantin Sekolah Menengah Pertama Negeri 2 Kuta Selatan Kabupaten Badung Tahun 2018.

\begin{tabular}{|c|c|c|c|}
\hline No & $\begin{array}{c}\text { Nama } \\
\text { Kantin }\end{array}$ & $\begin{array}{c}\text { Jumlah } \\
\text { Nilai }\end{array}$ & $\begin{array}{c}\text { Kategori } \\
\text { Hasil }\end{array}$ \\
\hline 1 & $\mathrm{~A}$ & 4 & $\begin{array}{c}\text { Memenuhi } \\
\text { Syarat }\end{array}$ \\
\hline 2 & B & 3 & $\begin{array}{c}\text { Tidak } \\
\text { Memenuhi }\end{array}$ \\
\hline 3 & $\mathrm{C}$ & 3 & $\begin{array}{c}\text { Syarat } \\
\text { Tidak } \\
\text { Memenuhi } \\
\text { Syarat }\end{array}$ \\
\hline 4 & D & 4 & $\begin{array}{c}\text { Memenuhi } \\
\text { Syarat }\end{array}$ \\
\hline
\end{tabular}

Berdasarkan pada tabel 1 mengenai pemeriksaan kondisi bangunan dan fasilitas kantin dengan jumlah sebanyak 4 kantin diperoleh 2 kantin tidak termasuk memenuhi syarat $(50 \%)$ yaitu pada kantin B dan C, serta 2 kantin memenuhi syarat (50\%) yaitu pada kantin A dan D. Menurut Keputusan Menteri 
Jurnal Kesehatan Lingkungan Vol.10 No. 1 Mei 2020:1-8

Kesehatan RI No.1429/MENKES/SK/XII

/2006 tentang pedoman penyelenggaraan

kesehatan lingkungan sekolah(8),

persyaratan bangunan kantin/warung

sekolah pemeriksaan dilakukan dengan 6 pertanyaan pada masing - masing pedagang disetiap kantin.

Berdasarkan 6 item yang diperiksa pada kondisi bangunan dan fasilitas pada kantin B ada item yang kurang yaitu tidak tersedia tempat cuci peralatan makanan dan minuman dengan air yang mengalir, tidak tersedianya tempat cuci tangan bagi pengunjung kantin / warung sekolah dan tidak tersedia tempat untuk menyimpan makanan jadi / siap jadi yang tertutup. Pada kantin C tidak tersedia tempat cuci peralatan makanan dan minuman dengan air yang mengalir, tidak tersedianya tempat cuci tangan bagi pengunjung kantin / warung sekolah dan lokasi kantin / warung sekolah yang berjarak kurang dari 20 Meter dengan Tempat Penampungan Sementara (TPS).

Menurut Sarah Syafirah(9) pada penelitian ini hanya sedikit kantin sekolah dasar yang memiliki tempat sampah yang memenuhi syarat. Masih ditemukannya penggunaan kardus dan kantong plastik sebagai tempat penampungan sampah, serta ditemukan banyak tempat sampah yang tidak memiliki tutup.

Berdasarkan penelitian yang telah dilakukan di kantin Sekolah Menengah Pertama Negeri 2 Kuta Selatan, higiene penyajian di ke 4 kantin tersebut didapatkan hasil sebagai berikut :

Tabel 2

Higiene penyajian di kantin Sekolah Menengah Pertama Negeri 2 Kuta Selatan Kabupaten Badung Tahun 2018.

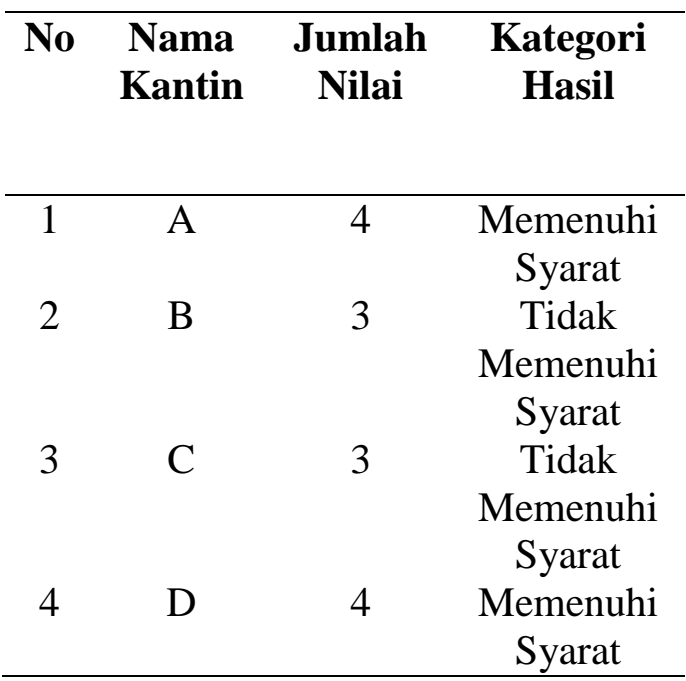

Berdasarkan pada tabel 2 mengenai pemeriksaan higiene penyajian pada kantin dengan jumlah sebanyak 4 kantin diperoleh 2 kantin tidak termasuk memenuhi syarat $(50 \%)$ yaitu pada kantin B dan C, serta 2 kantin memenuhi syarat (50\%) yaitu pada kantin A dan D. Menurut Keputusan Menteri Kesehatan 
Jurnal Kesehatan Lingkungan Vol.10 No. 1 Mei 2020:1-8

RI No.1429/MENKES/SK/XII /2006 tentang pedoman penyelenggaraan kesehatan lingkungan sekolah(8), persyaratan bangunan kantin/warung sekolah pemeriksaan dilakukan dengan 6 pertanyaan pada masing - masing pedagang disetiap kantin.

Berdasarkan 6 item yang diperiksa pada higiene penyajian kantin masih ada item yang kurang yaitu pada kantin B dan kantin $\mathrm{C}$ karena makanan jajanan yang dijual belum dalam keadaan tertutup dan belum bebas dari debu, lalat atau binatang lainnya, tempat pengolahan / dapur / penyiapan makanan belum bersih dan belum memenuhi syarat kesehatan sesuai ketentuan yang berlaku seperti terhindar dari debu, dan binatang, serta peralatan yang sudah dipakai belum dicuci dengan air yang mengalir / dalam 2 wadah yang berbeda dan tidak menggunakan sabun.

Menurut Nurmala Sari, dkk(10) didalam hasil penelitiannya yaitu bahan makanan yang dijual mengalami perjalanan yang panjang dan luas, kita tidak mengetahui darimana sumber makanan tersebut berasal sehingga dapat mempengaruhi kualitasnya. Pemilihan bahan baku oleh penjamah makanan berasal dari pasar tradisional yang diawasi oleh pemerintah.

Berdasarkan penelitian yang telah dilakukan di kantin Sekolah Menengah Pertama Negeri 2 Kuta Selatan, kondisi penyimpanan peralatan dan makanan di ke 4 kantin tersebut didapatkan hasil sebagai berikut :

Tabel 3

Penyimpanan peralatan dan makanan di kantin Sekolah Menengah Pertama Negeri 2 Kuta Selatan Kabupaten Badung Tahun 2018.

\begin{tabular}{|c|c|c|c|}
\hline No & $\begin{array}{c}\text { Nama } \\
\text { Kantin }\end{array}$ & $\begin{array}{c}\text { Jumlah } \\
\text { Nilai }\end{array}$ & $\begin{array}{c}\text { Kategori } \\
\text { Hasil }\end{array}$ \\
\hline 1 & $\mathrm{~A}$ & 4 & $\begin{array}{l}\text { Memenuhi } \\
\text { Syarat }\end{array}$ \\
\hline 2 & B & 4 & $\begin{array}{c}\text { Memenuhi } \\
\text { Syarat }\end{array}$ \\
\hline 3 & $\mathrm{C}$ & 4 & $\begin{array}{l}\text { Memenuhi } \\
\text { Syarat }\end{array}$ \\
\hline 4 & D & 4 & $\begin{array}{l}\text { Memenuhi } \\
\text { Syarat }\end{array}$ \\
\hline
\end{tabular}

Berdasarkan pada tabel 3 mengenai pemeriksaan penyimpanan peralatan dan makanan pada kantin dengan jumlah sebanyak 4 kantin seluruhnya termasuk memenuhi syarat (100\%). Menurut Keputusan Menteri Kesehatan RI No.1429/MENKES/SK/XII /2006 tentang pedoman penyelenggaraan kesehatan lingkungan sekolah(8), persyaratan bangunan kantin/warung 
sekolah pemeriksaan dilakukan dengan 6 pertanyaan pada masing - masing pedagang disetiap kantin.

Pada seluruh kantin sudah memenuhi syarat namun masih ada 2 syarat yang belum terpenuhi dari kantin tersebut yaitu pada seluruh kantin tempat penyimpanan makanan yang dijual pada warung / kantin belum terlindung dari debu dan tempat penyimpanan makanan yang dijual pada warung / kantin belum terhindar dari serangga dan hewan lain.

Menurut Sarah Syafirah(9) didalam hasil penelitiannya pada saat observasi dilakukan, ditemukan satu sekolah yang menggunakan styrofoam sebagai wadah penyajian mie rebus atau goreng. Berdasarkan kajian di Jepang oleh sebuah Divisi Keamanan Pangan, residu styrofoam pada makanan sangat berbahaya, karena dapat menyebabkan gangguan pada sistem endokrinologi dan reproduksi manusia.

Berdasarkan penelitian yang telah dilakukan di kantin Sekolah Menengah Pertama Negeri 2 Kuta Selatan, intensitas cahaya di ke 4 kantin tersebut didapatkan hasil sebagai berikut :
Tabel 4

Intensitas cahaya di kantin Sekolah Menengah Pertama Negeri 2 Kuta Selatan Kabupaten Badung Tahun 2018.

\begin{tabular}{ccccc}
\hline $\begin{array}{c}\text { N } \\
\text { o }\end{array}$ & $\begin{array}{c}\text { Kantin } \\
\text { Yang } \\
\text { Diukur }\end{array}$ & Hasil & $\begin{array}{c}\text { Katagori } \\
\text { Hasil }\end{array}$ & $\begin{array}{c}\text { Persy } \\
\text { aratan }\end{array}$ \\
\hline 1 & Kantin & 51 & $\begin{array}{c}\text { Tidak } \\
\text { memenuhi } \\
\text { syarat }\end{array}$ & \\
& A & lux & Tidak & \\
& Kantin & 35 & $\begin{array}{c}\text { memenuhi } \\
\text { syarat }\end{array}$ & 100 \\
2 & B & lux & lux \\
& Kantin & 100 & $\begin{array}{c}\text { Memenuhi } \\
\text { syarat }\end{array}$ & \\
3 & C & lux & Tidak & \\
& Kantin & 160 & memenuhi & \\
4 & D & lux & syarat & \\
& & & &
\end{tabular}

Berdasarkan pada tabel 4 mengenai pemeriksaan intensitas cahaya pada kantin dilakukan dengan alat lux meter disetiap kantin. Hasil pemeriksaan intensitas cahaya pada kantin di Sekolah Menengah Pertama Negeri 2 Kuta Selatan, yang berpedoman pada Keputusan Menteri Kesehatan RI No.1429/MENKES/SK/XII /2006 tentang pedoman penyelenggaraan kesehatan lingkungan sekolah(8), persyaratan bangunan kantin/warung sekolah dari 4 kantin di Sekolah Menengah Pertama Negeri 2 Kuta Selatan tersebut mendapatkan hasil yaitu terdapat 3 kantin termasuk dalam kategori tidak memenuhi 
Jurnal Kesehatan Lingkungan Vol.10 No. 1 Mei 2020:1-8

syarat (75\%) dan 1 kantin termasuk dalam kategori memenuhi syarat (25\%).

Menurut Nurmala Sari, $\operatorname{dkk}(10)$ didalam penelitiannya yaitu Kondisi Lokasi dan Bangunan di kantin Sekolah Menengah Atas di Kecamatan Rantau Utara Kabupaten Labuhan Batu Tahun 2012. Ventilasi sendiri tersedia serta pencahayaannya yaitu 100 lux dan berfungsi dengan baik. Untuk atap semua kantin tidak bocor dan tidak menjadi sarang tikus dan serangga, Sedangkan langit- langit juga cukup rata dan bersih namun masih ada terdapat lubang lubang.

\section{SIMPULAN DAN SARAN}

Berdasarkan penelitian yang telah dilakukan di kantin Sekolah Menengah Pertama Negeri 2 Kuta Selatan Kabupaten Badung, dapat disimpulkan bahwa: (1) Pada kondisi bangunan dan fasilitas kantin didapatkan hasil tidak memenuhi syarat dengan presentase 50\% dan memenuhi syarat dengan presentase $50 \%$. (2) Higiene penyajian didapatkan hasil tidak memenuhi syarat dengan presentase $50 \%$ dan memenuhi syarat dengan presentase $50 \%$. (3) Pada penyimpanan peralatan makanan dan minuman seluruh kantin termasuk memenuhi syarat dengan presentase 100\%. (4) Pada pengukuran intensitas cahaya didapatkan hasil yaitu kantin $75 \%$ tidak memenuhi syarat dan $25 \%$ memenuhi syarat.

Berdasarkan penelitian yang telah dilakukan di kantin Sekolah Menengah Pertama Negeri 2 Kuta Selatan Kabupaten Badung, saran yang dapat disampaikan yaitu (1) Kepada pihak pengelola kantin agar lebih menjaga kebersihan di lingkungan sekitar kantin serta menyiapkan tempat untuk menyimpan makanan jadi yang tertutup. (2) Siswa-siswi dan guru agar lebih memperhatikan kualitas makanan yang dijajakan seperti menghindari makanan siap saji yang tidak ditutup saat disajikan.

\section{DAFTAR PUSTAKA}

1. RW P. Identifikasi Bakteri

Eschericia coli dan Salmonella sp.

Pada Jajanan Batagor Di Sekolah

Dasar Negeri Di Kelurahan

Pisangan, Cirendeu, Dan Cempaka

Putih Ciputat Timur. Bachelor's thesis, FKIK UIN Jakarta; 2016.

2. Amourisva SA. Kontradiksi

Kebiasaan Jajan Pada Anak Usia 
Jurnal Kesehatan Lingkungan Vol.10 No. 1 Mei 2020:1-8

Sekolah Dasar. 2015.

3. Mudzkirah I. Identifikasi

Penggunaan Zat Pengawet Boraks

dan Formalin Pada Makanan

Jajanan di Kantin Uin Alauddin

Makassar. Doctoral dissertation,

Universitas Islam Negeri Alauddin

Makassar; 2016.

4. Nurikhsani FA. Analisis Kantin

Makanan Sehat Di Sekolah Dasar.

Universitas Muhammadiyah

Purwokerto; 2017.

5. Rahayu EM. Manajemen Layanan

Kantin Sehat Di Sekolah

Adiwiyata (Studi Kasus Di

SMPN10 Malang. 2017.

6. Notoatmodjo S. Metodologi

penelitian kesehatan. Jakarta:

Rineka Cipta; 2010.

7. Sudradjat, M., \& Achyar ST.

Statistika Konsep Dasar

Pengumpulan \& Pengolahan Data.

Bandung: Widya Padjadjaran;

2010.

8. Kemenkes. Keputusan Menteri

Kesehatan Republik Indonesia

Nomor 1429/Menkes/SK/XII/2006

Tentang Pedoman

Penyelenggaraan Kesehatan

Lingkungan Sekolah. Jakarta;
2006.

9. Syafirah, S., \& Andrias DR.

Higiene Penjamah Makanan dan

Sanitasi Kantin Sekolah Dasar

Negeri di Kecamatan Mulyorejo.

Media Gizi Indones.

2012;10(2):111-6.

10. Sari, N., Marsaulina, I. \& C.

Higiene Sanitasi Pengelolaan

Makanan dan Perilaku Penjamah

Makanan di Kantin Sekolah

Menengah Atas (SMA) Negeri dan

Swasta di Kecamatan Rantau Utara

Kabupaten Labuhan Batu.

Lingkung dan Keselam Kerja.

2013;2(1). 